\title{
A Comparative Study of Immunochromatographic Test (ICT) and Bone Marrow Aspiration for the Diagnosis of Kala-Azar in Children
}

\author{
Kundu $\mathrm{NK}^{1 *}$, Siddique $\mathrm{AB}^{2}$, Sarkar MAM${ }^{3}$, Uddin $\mathrm{MB}^{4}$
}

\author{
${ }^{1}$ Dr. Nitish Kumar Kundu, Assistant Professor, Department of Paediatrics, Pabna Medical College, Pabna, Bangladesh \\ ${ }^{2}$ Prof. Dr. A.B.Siddique, Professor and head (rtd.), Department of Paediatrics, Rajshahi Medical College, Rajshahi, Bangladesh \\ ${ }^{3}$ Prof. Dr. Md Abdul Mukit Sarkar, Professor and Head (rtd.), Department of Community Medicine, Rajshahi Medical College, \\ Rajshahi, Bangladesh \\ ${ }^{4}$ Prof. Dr. Md Belal Uddin, Professor and Head, Department of Paediatrics, Rajshahi Medical College, Rajshahi, Bangladesh
}

DOI: $10.36347 /$ sjams.2021.v09i02.017

| Received: 23.01.2021 | Accepted: 11.02.2021 | Published: 26.02.2021

*Corresponding author: Dr. Nitish Kumar Kundu

Abstract

Original Research Article

Introduction: Kala-azar or visceral leishmaniasis is a parasitic disease caused by Leishmania of the L. donovani complex. The Indian term kala-azar for this disease denotes black sickness and also hyperpigmentation seen in those patients. Immunochromatographic test (rk39) for VL is a qualitative, membrane based immunoassay for the detection of antibodies to visceral leishmaniasis in human serum. Aim of the study: To evaluate the immunochromatographic test (ICT) and bone marrow aspiration test for the diagnosis of kala-azar in children. Material \& Methods: This hospital based descriptive cross-sectional study was conducted in all the Paediatric units of Rajshahi Medical College Hospital from the period of April 2006 - December 2007. A total of 70 suspected cases of kala-azar patients were included in this study. Forty six (46) patients were diagnosed as a case of kala-azar, 24 patients were other than kalaazar. All data were analyzed by using SPSS (Statistical Package for Social Science) software package for entry, classification, analysis and interpretation of results. Results: A total of 70 suspected case of Kala-azar (Fever more than two weeks, pallor, hepatosplenomegaly) patients were enrolled in this study. Among them 46 patients (65.71\%) were diagnosed as a case of Kala-azar, 24 patients (34.29\%) were other than kala-azar. Among the kala-azar patients, most affected age group was 5-10 years. Male and female ratio was 1.71:1.Bone marrow study for LD body and ICT strip test performed in all 70 suspected case of Kala-azar. Among them LD bodies were found in 29 patients (41.43\%) and LD body was not found in 41 patients (58.57\%). Among them 24 cases were diagnosed other than Kalaazar.Among the Kala-azar cases (46 patients) LD body was not found in 17 cases (36.96\%). Among the suspected Kala-azar patients 43 patients $(61.43 \%)$ were ICT positive, 27 patients $(38.57 \%)$ were ICT negative. No patient of 'other than Kala-azar'gave ICT positive result. Among the Kala-azar cases, 43 patients (93.48\%) were ICT positive, 3 cases $(6.52 \%)$ were ICT negative. Sensitivity and specificity of bone marrow study for LD body were $63.04 \%$ and $100 \%$. Predictive of value of positive and negative test of bone marrow study for LD body were $100 \%$ and $58.83 \%$. Sensitivity and specificity of ICT strip test for kala-azar were $93.5 \%$ and $100 \%$. Predictive value of positive and negative test of ICT was $100 \%$ and $88.9 \%$. Conclusion: Immunochromatographic test (rk39 ICT) is more sensitive and specific for the diagnosis of kala-azar in children. Immunochromatographic test (rk39 ICT) is rapid, easy, noninvasive, field applicable and cost effective for the diagnosis of kala-azar.

Keywords: Kala-azar, Bone Marrow, Immunochromatographic, Parasitic, Leishmania.

Copyright $\odot 2021$ The Author(s): This is an open-access article distributed under the terms of the Creative Commons Attribution 4.0 International License (CC BY-NC 4.0) which permits unrestricted use, distribution, and reproduction in any medium for non-commercial use provided the original author and source are credited.

\section{INTRODUCTION}

Kala-azar or visceral leishmaniasis is a parasitic disease caused by Leishmania of the $L$. donovani complex (L. donovani, L. infantum, and L. chagasi) [1]. It is transmitted by the bite of infected female sandflies of the genus Phlebotomus (old world) and Lutzomyia (new world). The Indian term kala-azar for this disease (Kala means black; azar means sickness) denotes black sickness and also hyperpigmentation seen in those patients [2]. More than $90 \%$ of world's cases of visceral leishmaniasis occur in Bangladesh, Northeastern India, Nepal, and Sudan \& Northeastern Brazil [3]. Historically kala-azar or visceral leishmaniasis (VL) is endemic in Bangladesh. In the sixties and very early seventies DDT spraying under the malaria eradication program successfully controlled VL transmission in Bangladesh and the Indian sub-continent. In the late 1970 s, kala-azar re- 
appeared in Bangladesh sporadically. Since then kalaazar cases have gradually increased. The current prevalence is estimated at 40,000 cases. The total population at risk is in excess of 20 million (18\%), with at least 27 districts affected (42\%) and 88 thanas (19\%) reporting kala-azar cases in 1993-94 [4]. The disease pattern is extremely focal with most cases reported from rural areas, exhibiting a familial and contiguous household clustering pattern among the lowest socioeconomic groups. A high index of suspicion of kalaazar should be reached when a patient present with history of fever for more than 2 (two) weeks not responding to conventional treatment, pallor, splenomegaly, hepatomegaly, hyperpigmentation, loss of weight and progressive emaciation with weakness [4]. The diagnosis of visceral leishmaniasis (VL) is complex under the most favourable circumstances. Definitive diagnosis requires demonstration of parasites by smear or culture in tissue, usually spleen, bone marrow, or lymph node, and thus entails at least one invasive procedure. Immunochromatographic test (rk39) for VL is a qualitative, membrane based immunoassay for the detection of antibodies to visceral leishmaniasis in human serum. A kinesin-related protein encoding gene has been discovered in Leishmania chagasi that contains a repetitive 117-bp sequence encoding 39 amino acid residues (K39) and is conserved in amastigote form of VL causing leishmania strains (L. donovani, L. infantum and L. chagasi). Detection of antibody to the recombinant product of K39 (rk39) has been used in the format of immunochromatographic test. This test is highly sensitive \& specific for the diagnosis of visceral leishmaniasis. This test does not cross react with other parasitic disease e.g., malaria and chages. Sundor et al. showed the sensitivity and specificity of ICT was $100 \%$ \& 98\% respectively [5]. Caryn Bern et al. also showed both the sensitivity \& specificity of ICT were $100 \%$ [6]. ICT strip test has the ideal format for use in rural area. It is rapid, easy, and non-invasive and requires no specific equipment.

\section{OBJeCtives}

\section{General objective}

- To evaluate the immunochromatographic test and bone marrow aspiration test for the diagnosis of kala-azar in children in rural area.

\section{Specific Objectives}

- To determine the sensitivity \& specificity of ICT in kala-azar.

- To determine the positive $\&$ negative predictive value of ICT in kala-azar.

- To determine the sensitivity and specificity of bone marrow aspiration test in kala-azar.

- To determine the positive \& negative predictive value of bone marrow aspiration test in kala-azar.

\section{Methodology and Materials}

This hospital based descriptive cross-sectional study was conducted in all the Paediatric units of Rajshahi Medical College Hospital from the period of April 2006 - December 2007. A total of 70 suspected cases of kala-azar patients were included in this study according to following exclusion and inclusion criteria. Among them 46 patients were diagnosed as a case of kala-azar, 24 patients were other than kala-azar. After selection of the patients by maintaining the mentioned case selection criteria all clinical information were recorded in a pre-designed questionnaire. Sample technique was purposive sampling. For bone marrow aspiration study, with all aseptic preparation the skin area of the aspiration site was injected with $2 \%$ Lignocaine up to periosteum. The tip of the trochar and cannula of bone marrow aspiration needle is introduced through the skin perpendicularly by boring motion. Pressure should be applied from Palm of the hand. The entry into the marrow cavity is indicated by a sudden lack of resistance. The trochar is removed and 2-3 $\mathrm{ml}$ of marrow is aspirated by suction using a $50 \mathrm{ml}$ syringe. Marrow smear is placed on the slide and the smear slide is prepared. The slide is prepared by making them dry in air for 20-30 minutes. The slide should be sent to the pathology department of the medical college for microscopical examination. The patient should be observed for 24 hours. For immunochromatographic test (ICT), after collection of whole blood remove the serum from the clot or RBC as soon as possible to avoid haemolysis Allow the sera to reach room temperature prior to testing. Remove the kala-azar Detect Test for VL from the foil pouch or vial. Add $20 \mu \mathrm{L}$ of sera to the test strip in the area beneath the arrow. Place the test strip into a test tube, or well of a 96 well tissue culture plate so that the end of the strip is facing downward as indicated by the arrows on the strip. Add 2-3 drops of the Chase Buffer solution provided with the test kit. Read results in 10 minutes the test is positive when a control line and test line appears in the test area. The test is negative when only the control line appears. After collection of the required number of sample all the data were checked and refined for any errors. After verification data were edited and a master data sheet prepared. Finally all data were analyzed by using SPSS (Statistical Package for Social Science) software package for entry, classification, analysis and interpretation of results.

\section{- Inclusion Criteria}

Clinically suspected case of kala-azar under age 13 years

\section{Suspected case of kala-azar}

- Fever for more than 2 weeks

- Weight loss and emaciation

- Gradual pallor

- Splenomegaly with or without hepatomegaly

- Patient come from endemic zone of kala-azar 
Kundu NK et al; Sch J App Med Sci, Feb, 2021; 9(2): 260-266

- Pigmentation of the skin

- Exclusion Criteria

- Patient's age above 13 years

- Patient with complication such as-

- Severe renal disease

- Hepatic disease

- Cardiac disease

\section{RESUlTS}

A total of 70 suspected cases of kala-azar (fever more than 2 weeks, pallor, hepatosplenomegaly) patients were enrolled in this study. Among them 46 patients $(65.71 \%)$ were diagnosed as a case of kalaazar, 24 patients $(34.29 \%)$ were other than kala-azar (Figure I). Among the kala-azar patients, most affected age group was 5-10 years. Total 30 patients $(65.22 \%)$ were recorded in this age group. 9 patients $(19.57 \%)$ were under 5 years. Only 7 patients $(15.22 \%)$ were more than 10 years of age (Figure II). Mean age of kalaazar patient was $7.17 \pm 2.73$ years (Table I). In this study, it was found that 29 patients $(63 \%)$ were male and 17 patients $(37 \%)$ were female. Male and female ratio was 1.71:1 (Figure III). Among the kala-azar patients, 38 cases $(82.6 \%)$ came from low socio-economic family. Only 8 patients $(17.4 \%)$ came from middle class family. No patient had high socio-economic status (Table II). In this study, it was found that 38 patients $(82.6 \%)$ live in mud wall house. Only 1 patient $(2.2 \%)$ lives in building. 2 patients $(4.3 \%)$ lives in tin shed house (Figure IV). In this study, all patients (100\%) complained of fever and feeling lump in abdomen. 45 patients (97.8\%) complained of weight loss. 44 patients (95.7\%) complained of pallor. Appetite was normal in $60.9 \%$ patient. Only $39 \%$ patient had reduced appetite. $56.5 \%$ presented with no skin change. $43.5 \%$ patient complained about blackish change of skin (Table III). On physical examination, 45 patients $(97.8 \%)$ were found ill looking and only 1 patient $(2.2 \%)$ was toxic. 44 patients $(95.7 \%)$ were found anaemic. Anaemia absent in 2 patients $(4.3 \%)$. Only 1 patient $(2.2 \%)$ was icteric. Lymph node was palpable in 2 cases $(4.3 \%)$ (Table IV). Among the 46 cases of kala-azar, 91.3\% patients were anaemic. 1 patient $(2.2 \%)$ was severely anaemic. 35 patients $(76.1 \%)$ were moderately anaemic. Leukopenia was found in 32 cases $(69.6 \%)$. Platelet count was $<50000 / \mathrm{m} 3$ of blood in 2 patients $(4.3 \%)$. Thrombocytopenia was found in $65 \%$ patients. $34.8 \%$ patients had normal platelet count. $93.48 \%$ patients had significant high ESR. Among them 23 patients $(50 \%)$ had very high ESR (Table V and VI). In this study 22 patients $(47.83 \%)$ showed the feature of pancytopenia.
Leukopenia was found in 14 patients (30\%) (Table VII). Bone marrow study for LD body was done for all suspected case of kala-azar (70 patients). Among them LD bodies were found in 29 patients $(41.43 \%)$. LD body was not found in 41 patients $(58.57 \%)$. Among them 24 cases were diagnosed other than kala-azar. Among the kala-azar cases (46 patients) LD body was not found in 17 cases $(36.96 \%)$ (Table VIII). ICT strip test was done for all the suspected kala-azar patients. Among them, 43 patients $(61.43 \%)$ were ICT positive. 27 patients $(38.57 \%)$ were ICT negative. No patient of 'other than kala-azar' gave ICT positive result. Among the kala-azar cases, 43 patients $(93.48 \%)$ were ICT positive. 3 cases $(6.52 \%)$ were ICT negative (Table IX). Sensitivity and specificity of bone marrow study for LD body were $63.04 \%$ and $100 \%$. Predictive of value of positive and negative test of bone marrow study for LD body were $100 \%$ and $58.83 \%$ (Table X). Sensitivity and specificity of ICT strip test for kala-azar were $93.5 \%$ and $100 \%$. Predictive value of positive and negative test of ICT were $100 \%$ and $88.9 \%$ (Table XI).

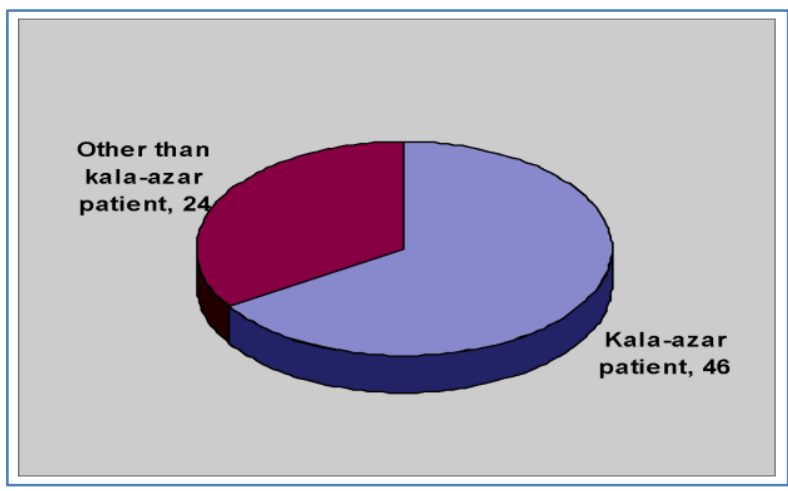

Fig-I: Distribution of suspected case of kala-azar patients

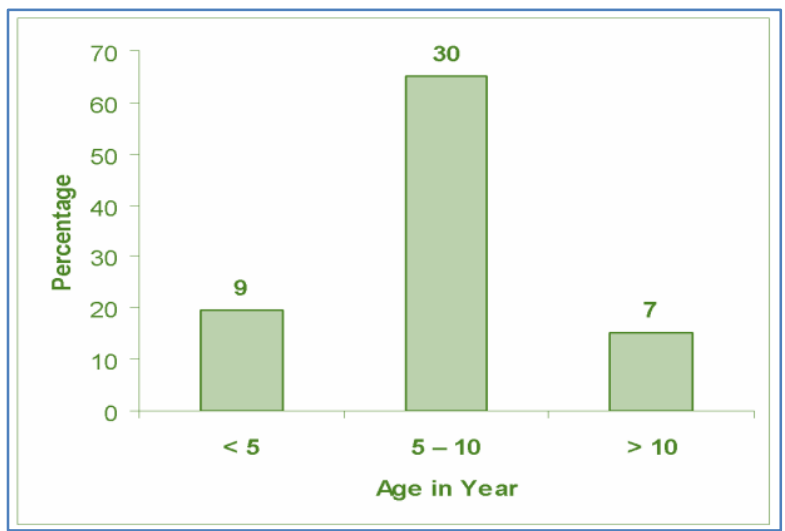

Fig- II: Age distribution of kala-azar patients $(n=46)$

Table-I: Distribution of mean age of suspected case of kala-azar $(n=70)$.

\begin{tabular}{|l|l|l|}
\hline Patient & Number of patient & Mean age (year) \\
\hline Kala-azar patient $(\mathrm{n}=46)$ & 46 & $7.17 \pm 2.73$ \\
\hline Other than kala-azar patient $(\mathrm{n}=24)$ & 24 & $6.79 \pm 3.28$ \\
\hline Total (suspected case of kala-azar) & 70 & $7.13 \pm 2.95$ \\
\hline
\end{tabular}




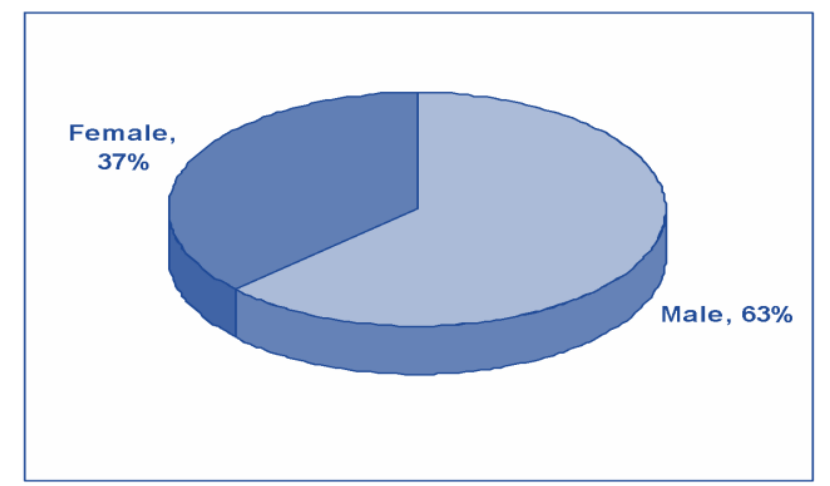

Fig-III: Sex distribution of kala-azar cases $(n=46)$.

Table-II: Socio-economic status of kala-azar patients $(n=46)$

\begin{tabular}{|l|l|l|}
\hline Socio-economic status & Frequency & Percent \\
\hline Low & 38 & 82.6 \\
\hline Middle class & 8 & 17.4 \\
\hline High & 0 & 0 \\
\hline Total & 46 & 100 \\
\hline
\end{tabular}

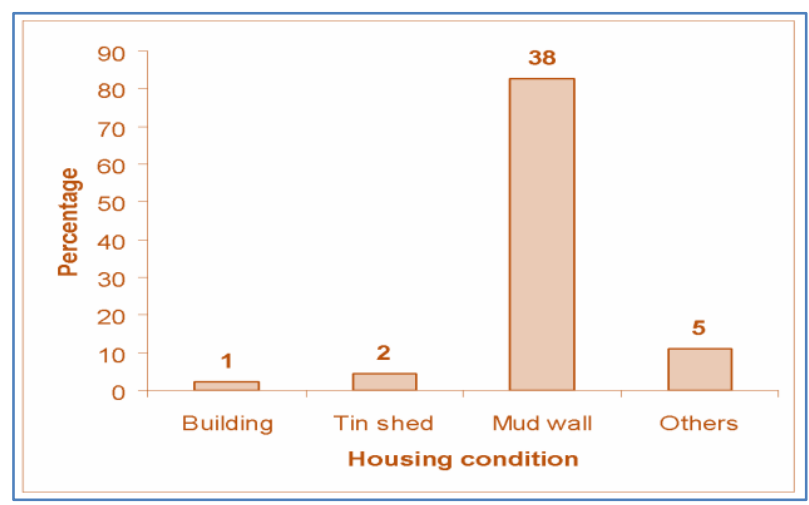

Fig-IV: Housing condition of kala-azar patients
Table-III: Clinical parameter of kala-azar patients $(n=46)$.

\begin{tabular}{|l|l|l|}
\hline Symptom & Frequency & Percent \\
\hline Fever & 46 & 100.00 \\
\hline Feeling lump in abdomen & 46 & 100.00 \\
\hline Weight loss & 45 & 97.80 \\
\hline Pallor & 44 & 95.70 \\
\hline Appetite : & 28 & 60.90 \\
\hline Normal & 18 & 39.10 \\
\hline Decrease & 26 & 56.50 \\
\hline Skin color: & 20 & 43.50 \\
\hline Same as before disease & 26 \\
\hline Blackish change &
\end{tabular}

Table-IV: Examination findings of kala-azar patients $(n=46)$

\begin{tabular}{|l|l|l|}
\hline Examination findings & Frequency & Percent \\
\hline Appearance: & 45 & 97.80 \\
\hline Ill looking & 1 & 2.20 \\
\hline Toxic & 46 & 100 \\
\hline Total & 44 & 95.70 \\
\hline Anaemia: & 2 & 4.30 \\
\hline Present & 46 & 100 \\
\hline Absent & 1 & \\
\hline Total & 45 & 97.80 \\
\hline Jaundice: & 46 & 100 \\
\hline Present & 2 \\
\hline Absent & 2 & 4.30 \\
\hline Total & 44 & 95.70 \\
\hline Lymph node: & 46 & 100 \\
\hline Palpable &
\end{tabular}

Table-V: Haematological parameter of kala-azar patients $(n=46)$

\begin{tabular}{|c|c|c|}
\hline Haematological parameter & Frequency & Percent \\
\hline \multicolumn{3}{|l|}{ Haemoglobin level: } \\
\hline$<6 \mathrm{~g} / \mathrm{dL}$ (severe anaemia) & 1 & 2.20 \\
\hline 6-9 g/dL (moderate anaemia) & 35 & 76.10 \\
\hline 9-11 g/dL(mild anaemia) & 6 & 13.00 \\
\hline$>11 \mathrm{~g} / \mathrm{dL}($ normal $)$ & 4 & 8.70 \\
\hline Total & 46 & 100 \\
\hline \multicolumn{3}{|l|}{ Total WBC count: } \\
\hline$<4000 / \mathrm{mm} 3$ of blood & 32 & 69.60 \\
\hline $4000-6000 / \mathrm{mm} 3$ of blood & 11 & 23.90 \\
\hline$>6000 / \mathrm{mm} 3$ of blood & 3 & 6.50 \\
\hline Total & 46 & 100 \\
\hline \multicolumn{3}{|l|}{ Platelet count: } \\
\hline$<50000 / \mathrm{mm} 3$ of blood & 2 & 4.30 \\
\hline $50000-100000 / \mathrm{mm} 3$ of blood & 17 & 37.00 \\
\hline $100000-150000 / \mathrm{mm} 3$ of blood & 11 & 23.90 \\
\hline$>150000 / \mathrm{mm} 3$ of blood & 16 & 34.80 \\
\hline Total & 46 & 100 \\
\hline \multicolumn{3}{|l|}{ ESR: } \\
\hline$>100$ in first hour & 23 & 50.00 \\
\hline 50-100 in first hour & 20 & 43.48 \\
\hline$<50$ in first hour & 3 & 6.52 \\
\hline Total & 46 & 100 \\
\hline
\end{tabular}


Table-VI: Haematological profile of kala-azar patients $(n=46)$

\begin{tabular}{|l|l|l|}
\hline Parameter & Mean & $\mathbf{\pm S D}$ \\
\hline $\mathrm{Hb} \%$ & 50.63 & \pm 10.96 \\
\hline Total count of WBC & 3526.09 & \pm 1401.02 \\
\hline ESR & 96.06 & \pm 32.21 \\
\hline Platelet count & 140260.87 & \pm 59675.20 \\
\hline
\end{tabular}

Table-VII: Haematological profile of kala-azar cases $(n=46)$

\begin{tabular}{|l|l|l|}
\hline Parameter & Frequency & Percent \\
\hline Kala-azar patient $(\mathrm{n}=46):$ & 22 & 47.83 \\
\hline Pancytopenia & 11 & 23.91 \\
\hline Leukopenia with relative lymphocytosis & 3 & 6.52 \\
\hline Leukopenia with normocytic normochromic anaemia & 6 & 13.04 \\
\hline Microcytic hypochromic anaemia & 6 & 8.70 \\
\hline Nonspecific finding & 4 & 100 \\
\hline Total & 46 & \\
\hline
\end{tabular}

Table-VIII: Bone marrow study for LD body of suspected case of kala-azar and kala-azar cases.

\begin{tabular}{|l|l|l|}
\hline \multirow{2}{*}{ Parameter } & Frequency & \\
\cline { 2 - 3 } & Suspected kala-azar cases $(\mathbf{n = 7 0})$ & Kala-azar cases(n=46) \\
\hline LD body found & $29(41.43 \%)$ & $29(63.04 \%)$ \\
\hline LD body not found & $41(58.57 \%)$ & $17(36.96 \%)$ \\
\hline Total & $70(100 \%)$ & $46(100 \%)$ \\
\hline
\end{tabular}

Table-IX: Result of ICT strip test for suspected case of kala-azar and kala-azar cases.

\begin{tabular}{|c|c|c|}
\hline \multirow{2}{*}{$\begin{array}{l}\text { Parameter } \\
\text { (ICT strip test) }\end{array}$} & \multicolumn{2}{|l|}{ Frequency } \\
\hline & Suspected kala-azar cases $(n=70)$ & Kala-azar cases $(n=46)$ \\
\hline Positive & $43(61.43 \%)$ & $43(93.48 \%)$ \\
\hline Negative & $27(38.57 \%)$ & $3(6.52 \%)$ \\
\hline Total & $70(100 \%)$ & $46(100 \%)$ \\
\hline
\end{tabular}

Table-X: Validity (accuracy) of bone marrow study for LD body for the diagnosis of kala-azar.

\begin{tabular}{|l|l|}
\hline Screening test & Percent \\
\hline Sensitivity & 63.04 \\
\hline Specificity & 100 \\
\hline Predictive value of a positive test & 100 \\
\hline Predictive value of a negative test & 58.83 \\
\hline
\end{tabular}

Table XI: Validity (accuracy) of ICT test for the diagnosis of kala-azar.

\begin{tabular}{|l|l|}
\hline Screening test & Percent \\
\hline Sensitivity & 93.5 \\
\hline Specificity & 100 \\
\hline Predictive value of a positive test & 100 \\
\hline Predictive value of a negative test & 88.9 \\
\hline
\end{tabular}

\section{DISCUSSION}

Kala-azar is more common in paediatric age group. In this study, the result revealed that the most affected age group was 5 to 10 years. In this study the results also revealed that male female patient ratio was 1.71:1. Aikat et al. [7] showed the similar reports. Sharma et al. [8] believed that protection from disease in female may due to influence of female sex hormone. But Thakur et al. [9] showed that male were more affected than female (male female ratio is 5.5: 1). Kalaazar is more confined to rural area [7, 9]. Most of the patient in this observation came from rural areas with lower socio-economic status having housing mostly made up of mud and adjacent to cattle shed. Kala-azar is more common in low socio-economic status population. Most of this population is either farmers or farm laborers and most farmers have cowsheds or bathans, where they keep cattle. Cattle shed also serves as play grounds for children. Other reported data is similar to this observation $[7,9,10]$. In this study it was found that all the patients of kala-azar were presented with fever and feeling lump in abdomen. Most of the patient $(97.8 \%)$ complained of weight loss. Majority of patient $(60.9 \%)$ had normal appetite in spite of prolong fever. Most of the patient (67.4\%) presented with fever of less than 3 months duration. Aikat et al. [7, 9, 10] found 3 type of fever in kala-azar patient (intermittent fever, daily rise with chills and rigor, continuous fever) with predominance of intermittent type of fever. In this study it was found that most of the patients were ill looking. Only one patient was found toxic. It was due to associated pneumonia. Most of the patients were anaemic. This study is consistent to other study [7]. In this study, about $76.1 \%$ of kala-azar patient were moderately anemic. Only one patient was severely anaemic and need blood transfusion. Most of the patient (69\%) presented with leukopenia. About $64 \%$ of kalaazar patient presented with thrombocytopenia. Platelet count was less than 50,000 per $\mathrm{mm}^{3}$ of blood in 2 
patients. There was one case in which thrombocytopenia $\left(<50000 / \mathrm{mm}^{3}\right.$ of blood $)$ was observed in total count and peripheral blood film with epistaxis. About 50\% patients had very high ESR (more than 100 in first hour). In this study, it was found that about $47 \%$ of patient presented with pancytopenia and $23 \%$ patient gave the picture of leukopenia with relative lymphocytosis. Aikat et al. [7] and Thakur et al. [9] found the same result in their studies. By bone marrow aspiration study, it was found that LD bodies were present in 29 of 46 kala-azar patient. So, $63 \%$ of kalaazar patients were LD body positive. In this study it was found that the sensitivity and specificity of bone marrow aspiration for kala-azar were $63 \%$ and $100 \%$. The predictive value of positive test was $100 \%$ and predictive value of negative test was $58.83 \%$. Zijlstra et al. [11], Piarroux et al. [12], Bern et al. [6] found the sensitivity of bone marrow aspiration for kala-azar $70.2 \%, 55 \%$ and $70 \%$ respectively. By the immunochromatographic (rk 39 ICT) strip test study it was found that 43 patient $(93.5 \%)$ were ICT strip test positive. In this study the results revealed that the sensitivity and specificity of ICT for the diagnosis of kala-azar were $93.5 \%$ and $100 \%$. The predictive value of the positive test was $100 \%$ and predictive value of negative test was $88.9 \%$. Zijlstra et al. [13], Sing S et al. [14], Mathur et al. [15] and Brundonisio O et al. [16] found the sensitivity of ICT strip test $67 \%, 100 \%, 100 \%$ and $99 \%$ respectively. It was observed that 43 patient of kala-azar gave a positive rk39 ICT result, giving it a sensitivity of $93.5 \%$. The dip stick test for rk39 antibody in immunocompetent patients has shown a sensitivity varying from 67 to $100 \%$ in various study [13]. This variation in sensitivity may be due to the different antigen formulation, difference in antibody response elicited in different population, a difference in circulating strain of leishmania or possible parasitic antigen alteration at high temperature in tropical countries [13, 15]. Bone marrow aspiration of these patients was negative for LD body. ICT was also negative for all these patients. Thus the ICT test was $100 \%$ specific. Sundar et al. [5] found $98 \%$ specificity of immunochromatographic test. So, this study is consistent with other study $[15,17,16]$. In the comparison to bone marrow study which is performed only Medical College Hospital; immunochromatographic test is highly sensitive \& specific, easy, suitable for rural area for the diagnosis of kala-azar in children.

\section{Limitations OF THE STUDY}

Sample size was limited. This was hospital based study. Community based study is also needed. This test is suitable for rural area. This test is cost effective.

\section{CONCLUSION AND RECOMMENDATIONS}

From the preceding study, from the results the author came to a conclusion that although the bone marrow study is the gold standard for diagnosis of kalaazar for direct evidence of LD body, it has low sensitivity and not suitable for rural area of Bangladesh. Immunochromatographic test (rk39 ICT) is more sensitive and specific for the diagnosis of kala-azar in children. Immunochromatographic test (rk39 ICT) is rapid, easy, non-invasive, field applicable and cost effective for the diagnosis of kala-azar. For the evaluation of these two tests (bone marrow aspiration for LD body and ICT strip test) the specificity and predictive values of positive test of both two tests were found same $(100 \%)$. Sensitivity and predictive value of negative test of ICT were more superior to bone marrow aspiration study. More study is needed before recommending replacement of direct evidence of LD body for the diagnosis of kala-azar.

\section{REFERENCES}

1. Isaacs D, Coulter JBS. Infections. Leishmaniasis. In: Melntosh Neil, Helms Peter, Smyth Rosalind, Forfar \& Arneil's Textbook in paediatric 6th ed, Churchill Livingstone. 2003: 1457.

2. Ghai OP, Gupta P, Paul VK. Ghai Essential Pediatrics. 6th Ed, Delhi, CBS publishers. 2004: 246.

3. Kersper DL, Faucis SA, Longol DL. Harison's principles of internal medicine; 16th eds McGrawHill. 2005:1235.

4. Malaria and Parasite Disease Control Unit, Directorate General of Health Service \& Institute of Epidemiology, Disease Control \& Research. Kala-Azar diagnostic, treatment \& recording chart. Trial Edition. 1995; 1: 5-11.

5. Sundar S, Read SG, Singh VP, Kumar PC, Murray HW. Rapid accurate field diagnosis of Indian visceral leishmaniasis. Lancet. 1998; 351: 563-565.

6. Bern C, Jha SN, Joshi AB, Thakur GD, Bista MB. Use of the recombinant rK39 dipstick test and the direct agglutination test in a setting endemic for visceral leishmaniasis in Nepal. Am J Trop Med Hyg. 2000; 63(3-4): 153-58.

7. Aikat BK, Sahaya S, Pathania AGS, Bhattacharia PK. Clinical profile of cases of kala-azar in Bihar. Indian J Med Res. 1979; 70: 563-70.

8. Sharma MC, Gupta AK, Saran R, Sinha SP. The effect of age and sex on incidence of kala-azar. J. Com. Dis. 1990; 22(4): 277-278.

9. Thakur CP. Epidemiological, clinical and therapeutic features of Bihar kala-azar (including post kala-azar dermal leishmaniasis). Trans R Soc Trop Med Hyg. 1984; 78: 391-8.

10. Sarkar CB, Haque MA. Kala-Azar: As seen in a district general hospital of Bangladesh. J Teach Asso (TAJ) Rajshahi. 1997; 10(1): 21-26. 
11. Zijlstra EE, Ali MS, El-Hassan AM. Kala-Azar; a comparative study of parasitological method and the indirect agglutination test in diagnosis. Transaction of the Royal Society of Tropical Medicine and Hygiene.1992; 86: 505-507.

12. Piarroux R, Gambarelli F. Comparison of PCR with the direct examination of bone marrow aspiration. Microculture and Serology for Diagnosis of Visceral leishmaniasis in immunocompromised patients. Journal of Clinical Microbiology. March; 1994: 746-749.

13. Zijlstra EE, Nur Y, Desjeux P, Khalil EAG, ElHassan AM, Groen J. Diagnosing visceral leishmaniasis with the recombinant K39 strip test: experience from Sudan, Trop Med Intnat Health. 2001; 6(2): 108-13.

14. Sing S, Kumari V, Sing N. Predicting Kala-azar disease manifestation in assymptomatic patient with latent leishmaniasis donovani infection by detection of antibody against recombinant k39 antigen. Clinical \& Diagnostic Laboratory Immunology May. 2002;9(3), 568-572.

15. Mathur P, Samantaray J, Chauhan NK. Evaluation of rapid immunochromatographic test for diagnosis of Kala-azar and post Kala-azar dermal leishmaniasis at a tertiary care centre of North India. Indian J Med Res. 122, December. 2005: 485-490.

16. Brandonisio O, Fumarola L, Maggi P, Cavaliere R, Spinelli R, Pastore G. Evaluation of a rapid immunochromatographic test for serodiagnosis of visceral leishmaniasis. European Journal of Clinical Microbiology and Infectious Diseases. 2002 Jun;21(6):461-4.

17. Badaro R, Benson D, Freire M. rK39: a cloned antigen of Leishmania chagasi that predict active visceral leishmaniasis. J Infect Dis. 1996; 173: 75861. 